\title{
Investigating EFL Learners' Engagement in Writing Research Papers
}

\author{
Rungkarn Pratumtong \\ Nareusan University, Phitsanulok, Thailand \\ Paweena Channuan \\ Naresuan University, Phitsanulok, Thailand \\ Wannaprapha Suksawas \\ Sukhothai Thammathirat Open University, Bangkok, Thailand
}

\begin{abstract}
This study explores voices from an Appraisal Theory perspective (Martin \& White, 2005). It aims to investigate how novice English as a Foreign Language (EFL) research writers deploy Engagement resources to review existing literature in the field. The study is based on a corpus of literature reviews from 25 research articles written by Thai undergraduate students enrolled in a research report writing class. Findings show that the writers demonstrated a strong preference to engage readers in the writers' justification of knowledge. The results revealed that Entertain, Acknowledge, and Counter resources were most often used in the articles. By contrast, novice research writers, to some extent, convince readers of their perspectives by using bare assertions without reference to other voices. It may be assumed that second language (L2) novice research writers are aware of the need to engage with readers and to strategically construe dialogic divergences in their written works.
\end{abstract}

Index Terms - research report writing, appraisal theory, engagement

\section{INTRODUCTION}

Writing in English as a second language is considered one of the most challenging skills for novice EFL writers, especially when writing in more complex genres such as a research paper. The writers need to both master language skills and to successfully communicate subject-specific knowledge in English according to research paper requirements. Therefore, it is essential that learners can employ appropriate linguistic devices to effectively interact with their readers. Engagement in writing plays a crucial role in expressing authors' viewpoints and dialogistic positioning to engage readers with their research. As such, it is a key element in Appraisal theory (Martin \& White, 2005).

Appraisal Theory is concerned with the linguistic resources by which a text/speaker comes to express, negotiate, and naturalize inter-subjective and ultimately ideological positions. Within this broad scope, the theory is concerned more particularly with the language of evaluation, attitude, and emotion, and with a set of resources which explicitly position a text's proposals and propositions interpersonally. That is, Appraisal Theory is concerned with the finer details of writing such as verb choices, ideas expressed, and the use of outside sources - termed external voices - as the text unfolds cumulatively.

When EFL students are learning to write a research report, they should be explicitly taught about linguistic features that help to incorporate outside sources effectively such as reporting verbs, modal auxiliaries, or intensifiers (Alramadan, 2020; Amonrattanasirichock \& Jaroongkhongdach, 2017; Mori, 2017; Ngo \& Unsworth, 2015). However, a significant challenge for L2 novice writers is to express their positioning in the context of other researchers' work and to engage themselves in these works, especially when writing a research paper. It is a challenge which must be met, however, since writers need to convince readers that the research conducted is reliable.

Academic writers need to support their rational opinions with defensible assertions and backing proof, including facts or assumptions to convince readers of their validity. Hence, an important aspect of academic writing is the ability to establish and convey information with a clear stance on a particular topic and to directly engage the reader in the context (Hayland, 2005). According to Hyland (2005), stance refers to the way writers present themselves and convey their judgements, opinions, and commitments, whereas engagement is defined as the way writers relate to their readers with respect to the positions advanced in the text. Using stance and engagement, writers can explicitly convey their affective position towards the text and reader, create writer-reader harmony, and ultimately construct an effectively persuasive context (Lee \& Deakin, 2016; Kitjaroonchai \& Duan, 2019).

The ability to persuade readers in academic writing texts creates solidarity and credibility among readers (Hyland, 2005). To successfully persuade readers in research writing, engagement plays a significant role in expressing the writer's standpoint and dialogistic positioning to convey and engage readers with their research. In other words, writers need to show competence as disciplinary insiders by making choices from the interpersonal systems of stance and 
engagement. Their textual voice must express their view and represent their position as well as persuade the audience of their justifications for what is being claimed (Hayland, 2008).

Engagement resource is one sub-system in Appraisal Theory developed by Martin and White (2005). 'Appraisal' is an umbrella term used to refer to semantic resources including the words, phrases, and structures speakers or writers employ to negotiate emotions, judgements, and evaluations. According to the framework, Appraisal Theory consists of three sub-systems: Attitude, Graduation, and Engagement. Attitude deals with feelings or emotional reactions and is further comprised of three complementing sub-systems: Affect (reacting to positive and negative feeling), Judgement (evaluation of human behaviors), and Appreciation (assessing the value of things or phenomena). Graduation concerns the upgrading and downgrading of attitudinal meanings and is further classified into Focus (sharpening or softening those assertions) and Force (assessing the degree of intensity and quantification). Engagement considers the positioning of oneself with respect to the viewpoints of others and with respect to one's own viewpoints (Martin \& White, 2005)

Engagement is concerned with the writer's positioning in their language and uses "language resources to place the writer's opinion related to the proposition and proposal contained in a language or text" (Martin \& White, 2005 p. 92 ). This system pertains to who makes the evaluation in the text where more than one opinion is being discussed. Engagement provides the means for the authorial voice to position itself with respect to other voices. Hence, it provides a way to 'engage' with alternative positions construed as being in play in the communicative context (Martin \& White, 2005 p. 92). In the context of research writing, Engagement implies that researchers agree that dialogic interaction includes the writer's positioning towards the subjects being discussed and, with respect to the background of others, who holds alternative viewpoints (Amonrattanasirichock \& Jaroongkhong, 2017).

Engagement consists primarily of monogloss and heterogloss. Monogloss indicates no uses of, or references to, another person's opinion (bare assertions) and subsequently "denies dialogic diversity" (Mei, 2006, p. 6). On the other hand, heterogloss conveys an awareness of other views and acknowledges diversity in the text's communicative backdrop (Martin \& White, 2005). In short, monogloss refers to the voice of the writer only, whereas heterogloss refers to the presence of other voices in the text. Heterogloss propositions are further categorized into four categories: disclaim, proclaim, entertain, and attribute. Under the disclaim category, writers suppress the dialogic space with readers by denying or countering any alternative or oppositional opinions from them. Disclaim is further sub-categorized into two sub-types: deny and counter. Within the proclaim heterogloss category, writers restrict the dialogic space with readers by representing the proposition against or by ruling out alternative viewpoints from them. Proclaim is further divided into three sub-types: concur, pronounce, and endorse. For the entertain heterogloss category, writers accept and are open to alternative viewpoints from readers by representing the proposition explicitly as grounded in its own subjectivity and as one of many possible propositions. Within the attribute heterogloss category, writers provide the most dialogic space for alternative viewpoints from readers by presenting propositions as grounded in the subjectivity of an external voice and as one of many propositions. Attribute is also divided into two sub-categories: acknowledge and distance. Furthermore, the four heterogloss categories are organized into dialogic contraction (the degree to which writers limit dialogically alternative voices) and dialogic expansion (the degree to which writers are open to other alternative voices). Hence, dialogic contraction includes the disclaim and proclaim categories, whereas dialogic expansion includes the entertain and attribute categories. To further clarify these categorizations, Figure 1 demonstrates the sub-categories within the Engagement subsystem with brief descriptions: 


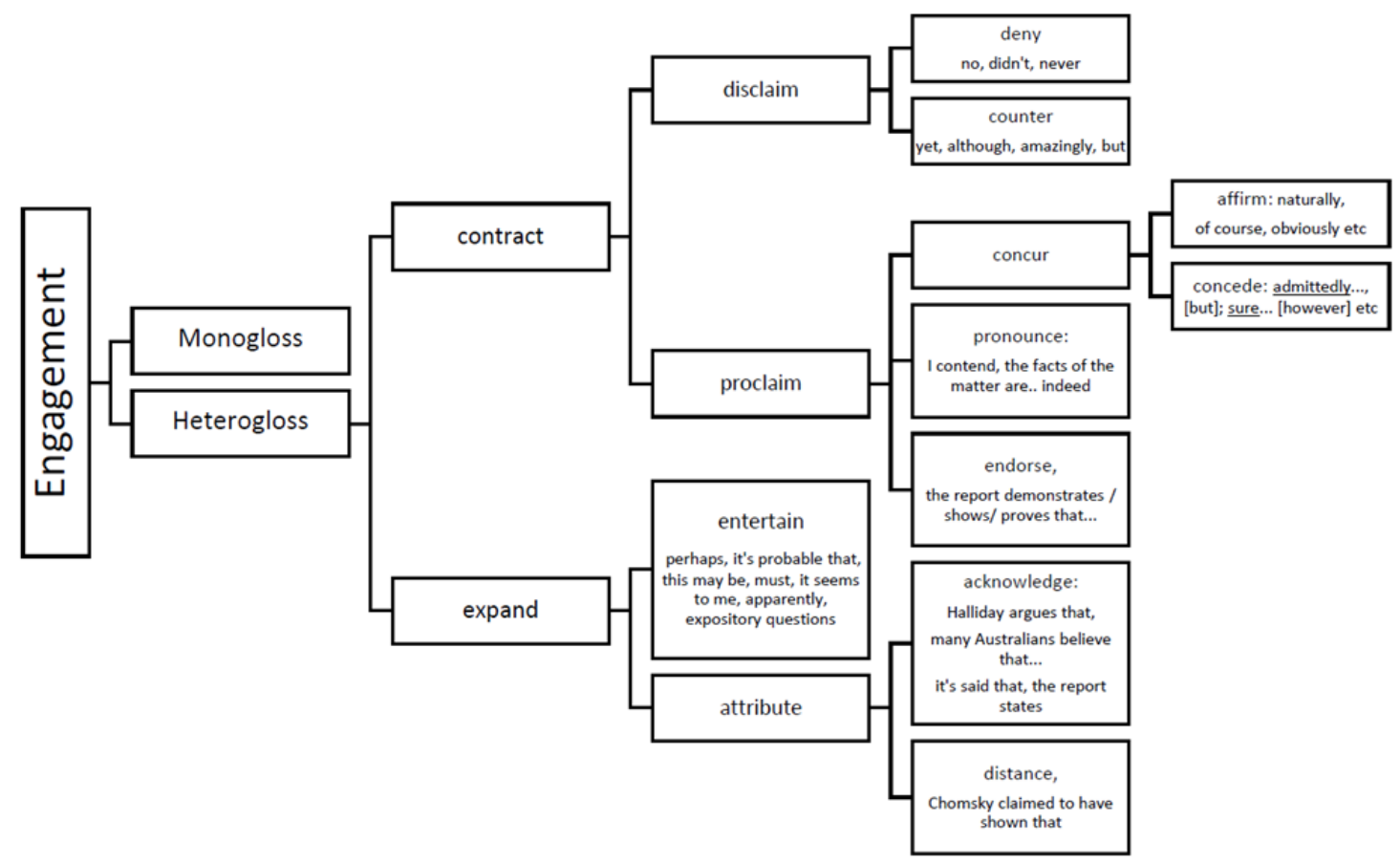

Figure 1. Engagement system taken from Martin and White (2005 p. 134)

Previous studies have investigated the use of evaluative language resources among L2 novice researchers. Wide application of the Engagement system proves it to be an effective framework for analyzing multiple voiced interactions, both internal (i.e., writers themselves) and external (i.e., readers, other researchers), with the interpersonal aim to build conviction in the research (Cheng \& Unsworth, 2016). Several important studies are listed below.

The study conducted by Mesa and Chang (2010) reports the results of their analysis of the language used by two instructors while teaching two undergraduate mathematics classes. It indicates that high student participation differed in relation to their level of dialogical engagement. The research focused on how instructors' language uses promoted or limited opportunities for student engagement with mathematical dialogs and thus established parameters for student agency in the classroom discourse. They found that how instructors used language determined different types and levels of student engagement. In addition, they found that how they employed their linguistic resources when engaging students to facilitate or forestall dialogic possibilities can influence student performance. Mesa and Chang (2010) concluded from their results that raising awareness of the role of language in sustaining dialogic engagement is an important area for professional and faculty development.

Another research study of interest pertaining to evaluative language choices in doctoral theses, specifically in the discussion section in the Applied Linguistics discipline is the study by Geng and Wharton (2016). Specifically, the authors conducted a comparative study of first language (L1) Chinese and L1 English writers by employing the Engagement sub-system. The results indicated no statistically significant differences in the patterns of language choices among the two groups, and that the L1 does not affect the writer's evaluative language choices. However, disciplinary culture can be dominant in disciplines with a stable and homogenous knowledge base and structure.

Because the focus of this study is on the literature review section in research writings, it is worth mentioning the study by Xie (2016) involving a textual analysis using Appraisal Theory of the literature review sections of Chinese Master of Arts (MA) theses. The finding revealed that Chinese MA students tended to explicitly convey evaluative language in their writing, expressed dominantly positive evaluations, and took a neutral position when referring to other voices, In the same vein, Amonrattanasirichock and Jaroongkhongdach (2017) investigated Engagement in the literature reviews of 20 research articles published in Thai and international journals in the field of Applied Linguistics. Their finding indicated non-significant differences in the use of Engagement between the two groups. However, the use of bare assertions without a support reference to convince readers was found to occur more often in Thai journals. Consequently, this may make the statements made in Thai journals sound more authoritative and imposing to readers.

As shown in the review of previous studies above, Engagement in Martin and White's (2005) Appraisal Theory is considered a useful device to explore the deployment of evaluation in terms of engagement in academic writing and research articles. In addition, it emerged that the literature review section of a thesis is considered a thorny challenge for L2 novice writers since they need to make appropriate references to other works and to demonstrate the evaluation of 
other's and their own work simultaneously (Bruce, 2014; Salom \& Monreal, 2014). In research articles, the bulk of evaluative language typically appears in the literature review as writers must synthesize relevant scholarly work and develop the credibility and value of their research. As the structure of a literature review can be complicated and challenging to implement, some studies confirm that inexperienced and novice writers have difficulty in expressing evaluative language (Bruce, 2014; Kwan, Chan \& Lam, 2012). Therefore, the deployment of Engagement-related evaluations in the literature review of L2 novice research writers is worth investigating, especially in the Thai context.

The present study sets out to analyze evaluation in terms of Engagement in literature review sections of English research articles produced in research report writing course in 2020. The analysis applies the Engagement sub-system developed in Martin and White's (2005) Appraisal Theory. It is anticipated that the results of the study will further contribute to the academic understanding of Engagement resources and how to use them. In addition, novice EFL writers and researchers will benefit from the results of the current study in terms of improving their academic writing skills. This study is guided by the following research questions:

1. How do Thai EFL writers position themselves when they write research reports?

2. What Engagement categories and sub-categories are used in the literature review section of research articles produced by Thai EFL students?

\section{Methodology}

\section{A. Data Collection}

This study drew on 25 English academic research articles written by third-year English major students enrolled in the second semester of the research report writing course at a University in Thailand in 2020. The focus was on the literature review section of the research articles. This study accumulated a small, specialized corpus set of data which were analyzed manually and contextually with the interpersonal meaning being highlighted and classified via an interpretive process. The frequency of each category was counted and compared. A small corpus was adequate for the "qualitative, contextually informed analyses" (Flowerdew, 2004 p.18) which formed the basis of the corpus annotation presented in this study. The total corpus contained 18,000 words. The average word length per text was 720 words, ranging from 458 words to 920 words overall.

\section{B. Data Analysis}

The literature review section of research articles relies heavily on evaluative language. This is because its purpose is to critically propose the researchers' viewpoints, construct the claims of knowledge, and persuade the reader that there is space for new knowledge (Hunston, 1994, 2011). To study evaluative language in this context, this study employed Martin and White's (2005) Appraisal Theory which examines "what is at stake interpersonally both in individual utterances and as the text unfolds cumulatively" (White, 2001, p.8). The theory introduces meaning-making among individuals as mainly focused on negotiating a position opposed to prior utterances and the actual or possible responses of others in a communicative context.

Accordingly, the collected data in this study were analyzed quantitatively based on the frequency of the Appraisal Theory's Engagement sub-system (Martin \& White, 2005). To begin, the proposition statements were coded based on whether they respected (heterogloss) or did not respect (monogloss) the opinions of others. Then, heteroglossic formulations were coded and categorized into their sub-categories in terms of whether space for dialogue was opened (expansive heterogloss) or shut down (contractive heterogloss). Finally, the choice of evaluative language used by the Thai undergraduate EFL students was analyze and its Engagement function was described.

Due to the different lengths of each corpus, this study computed the normalized frequency per 1,000 words $(/ \mathrm{k})$ of the occurrence of the Engagement resource. In addition, inter-rater reliability was used to ensure the reliability of the data coding procedure. Two researchers carefully read and coded each clause using the categories of Engagement defined previously. To test the consistency and reliability of the parsing and coding, two random corpora of about the same length were selected for rechecking. The average level agreement in parsing clauses was 82 percent, which is considered acceptable.

\section{RESEARCH FINDINGS}

The aim of this study was to investigate evaluation in terms of Engagement in the literature review section of L2 Thai undergraduate students. First, the finding of the overall frequency of Engagement categories mentioned above is presented. Later, details of the Engagement's sub-categories used by the students are reported.

\section{A. Distribution of Engagement Resource in the Literature Review Section}

The results of the analysis indicate that the literature review sections of EFL research articles written by Thai undergraduate students use more heteroglossic (64.81\%) than monoglossic (35.19\%) formulations, as shown in Table 1. 
TABLE 1

FreQuenCy AND PERCENTAGE Distribution OF MONOGLOSSIA AND HETEROGLOSSIA In THE LiTERATURE REVIEW SECTIONS

\begin{tabular}{|l|l|l|}
\hline Category & Frequency (/k) & Percentage \\
\hline Heteroglossia & 28.0 & $64.81 \%$ \\
\hline Monoglossia & 15.2 & $35.19 \%$ \\
\hline Total & $43.2 \%$ & 100 \\
\hline
\end{tabular}

The results presented in Table 1 help to answers the first research question that students tend to allow readers to engage in their writing when they discussed external voices. As indicated in Table 1, the students as novice research writers provided their viewpoints in such a way that allowed space for other voices (heteroglossic) rather than the writers' own voice propositions (monoglossic). Since monoglossic text often sounds descriptive, report-like, and impersonal, it seeks less to engage than to give facts and overtly concedes no room for the negotiation of meaning (Mesa \& Chang, 2010). The students mainly used monogloss to present factual information or to report other viewpoints in their written text, as demonstrated in the following extract:

(1) Thailand is the country which has only one official language, Thai. Teaching English as a Foreign Language (EFL) in Thailand is not easy because there are obstacles in term of language usage, region, society etc. [MONO]

[source: Student 2, 2020]

In addition, the qualitative examination of the texts in this study found that monogloss (bare assertion) utilized metalanguage such as a summary of the section, and cross-references to results already presented. For example:

(2) In summary, all five related research describes the problem of the use of prepositions in foreign countries by examining the writing results. It is clear that social media plays a potential role in English learning. [MONO]

[source: Student 8, 2020]

\section{B. Distribution of Heteroglossic Subcategories in the Literature Review Section}

In terms of heteroglossic sub-category preferences, it was found that dialogic expansions $(53.31 \%)$ were used more often than dialogic contractions (46.69\%), even though the ratio gap was not a sharp one. This result implies that Thai EFL students position themselves with respect to external voices cautiously by welcoming rather than closing-down the possibility of alternative viewpoints.

As indicated in Table 2, among all heteroglossic resources, 'entertain' was utilized most often (38.97\%). This was followed by 'counter' (13.60\%) and 'acknowledge' (13.24\%). The least used heteroglossic resource was 'distance' $(1.10 \%)$, which was categorized under dialogic expansion. This might indicate that students in this study are aware of the nature of academic writing in referring to alternative viewpoints. They actively made allowances for dialogically alternative positions and voices (dialogic expansion) and, alternatively, acted to challenge or restrict the scope of such positions (dialogic contraction) simultaneously.

TABLE 2

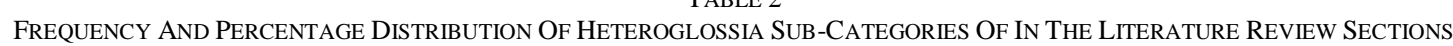

\begin{tabular}{|c|c|c|c|c|}
\hline \multicolumn{3}{|c|}{ Heteroglossia Subcategories } & $\begin{array}{l}\text { Frequency } \\
(/ \mathbf{k})\end{array}$ & Percentage \\
\hline \multirow[t]{5}{*}{ Contract } & Disclaim & Deny & 3.33 & $7.35 \%$ \\
\hline & & Counter & 6.17 & $13.60 \%$ \\
\hline & Proclaim & concur & 0.17 & $0.37 \%$ \\
\hline & & Pronounce & 0 & $0 \%$ \\
\hline & & Endorse & 11.50 & $25.37 \%$ \\
\hline \multicolumn{3}{|c|}{ Total Contraction } & 21.17 & $46.69 \%$ \\
\hline \multirow[t]{3}{*}{ Expand } & Entertain & & 17.67 & $38.97 \%$ \\
\hline & Attribute & Acknowledge & 6.00 & $13.24 \%$ \\
\hline & & Distance & 0.50 & $1.10 \%$ \\
\hline \multicolumn{3}{|c|}{ Total Expansion } & 24.17 & $53.31 \%$ \\
\hline \multicolumn{3}{|c|}{ Grand Total } & 45.34 & $100 \%$ \\
\hline
\end{tabular}

Note:/k = normalized frequency per 1,000 words.

To clearly understand the use of heteroglossic sub-category resources by Thai EFL students, some of the remarkable dialogistic results from students' works are extracted and illustrated as an example of the data analysis.

The first point of interest is the relatively high proportion of 'entertain' uses, categorized as dialogic expansion. According to Martin and White (2005), 'entertain' options open up the dialogic space for alternative positions via modal auxiliaries (may, might, could, must, etc.), modal adjuncts (perhaps, probably, definitely, etc.), modal attributes (it's possible that ..., it's likely that ..., etc.), circumstances of the in my view type, certain mental verb/attribute projections (I suspect that ..., I think, I believe, I convinced that, I doubt, etc.), and evidence/appearance-based postulations (it seems, it appears, apparently, the research suggests ..., it's almost certain that ...). In this corpus, the 'entertain' options illustrated below in (3) and (4) are used to welcome other views points and to indicate the uncertainty of the truth value on the part of a writer, respectively. 
(3) Learners who have some experience in listening to and understanding a number of different accents are more likely [Hetero_expand:entertain] to comprehend in listening than those who have only heard one or two.

[Source: Student 24, 2020]

(4) Students' motivation may [Hetero_expand:entertain] have significant influences on essential academic outcomes.

[Source: Student 3, 2020]

In contrast to dialogic expansion which opens-up and acknowledges alternative stances and points of view, dialogic contraction acknowledges alternative voices but shuts down the possibility of dialogue. Under heteroglossic subcategory, 'counter' occupies the second most-often used option. This option invokes prior utterance or alternative views, but unlike dialogic expansion, they introduce positions to refute or replace them. 'Counter' is often realized by conjunctions and connectives (e.g., although, however, yet, but), comment adjuncts/adverbials (e.g., surprisingly), and adjuncts (e.g., even, only, just, still) (Martin \& White, 2005). In this study, students demonstrated their academic writing ability by justifying the writer's knowledge claims and by restricting other viewpoints, simultaneously. This is shown in the excerpts below:

(5) Although [Hetero_contract:counter] they have a few barriers, they feel more confident and less anxious to communicate in English with foreigners.

[Source: Student 14, 2020]

(6) Students often think that the ability to speak a language is the product of language learning, but [Hetero_contract:counter] speaking is also a crucial part of the language learning process.

[Source: Student 11, 2020]

Another noteworthy feature is 'acknowledge', which was used almost as frequently as the 'counter' resource. 'Acknowledge' is categorized under dialogic expansion, which considers external voices as one of many possible positions, although it is not indicated clearly where the writer's voice stands with respect to external voices (Martin \& White, 2055). This occurs within the domain of reporting verbs such as say, report, state, declare, announce, believe, think, announce that..., according to ..., In one's view, etc., and hearsay such as ...reportedly, It is said that ...etc. The example of 'acknowledge' found during this study is presented below:

(7) According to [Hetero_expand:acknowledge] a study by Tok (2009), major obstacles to communicating in English for Turkish EFL students was anxiety and unwillingness.

[Source: Student 14, 2020]

(8) Rathna (2013) stated [Hetero_expand:acknowledge] that the correct use of tense will help the language learners to communicate with others clearly and effectively.

[Source: Student 5, 2020]

Considered as another category of citation, the 'distance' resource was scarcely used in this study. Distancing formulations are categorized under dialogic expansion, similar to 'acknowledge'. However, unlike 'acknowledge', 'distance' presents the authorial voice as explicitly declining to take responsibility for the proposition and maximizes the space for dialogistic alternatives. It is often realized by the reporting verb, to claim, and by certain uses of 'scare' quotes (Martin \& White, 2055). In other words, writers hesitate to judge the referenced source explicitly or negatively, as illustrated in the below example:

(9) It has been claimed [Hetero_expand:distance] by psychologists that attitude consists of three elements, which are stated to be affective, cognitive, and behavioral.

[Source: Student 7, 2020]

Based on the above finding, Thai EFL students employed a wide range of Engagement resources, as well as a better balance between expansive and contractive options. The students demonstrate the ability to adopt a stance towards the value positions being referenced by the text and with respect to those they address, which is the basic universal rule of research writing.

\section{DiSCUSSION AND CONCLUSION}

This study explored how the authorial voice was constructed in the citations included in the literature review sections written by Thai undergraduate students. Analysis of the texts revealed important features on how students use certain linguistic forms to open or suppress dialogic interaction in the academic writing context.

From a holistic view of the Engagement resource, the finding showed that heteroglossic formulation was used relatively frequently in the segments analyzed compared to the frequency of monglossic formulations. This suggests that in the literature review section, where writers need to refer appropriately to other sources and to respond to prior assertions, students can position themselves towards the cited literature irrespective of whether they are in alignment or misalignment with the cited source. The influence of heterogloss found in this study agrees with previous research (Mo, 2010; Du; 2010; Amornrattanasirichok \& Jaroongkhongdach, 2017) in that the novice writers remain in uniformity with the standard rule of research writing when referring to alternative stances or viewpoints. 
On the other hand, the nature of the literature review section requires writers to state facts, clarify statements, and propose new statements. In turn, the high frequency of monoglossic resources in this study may reflect the students' tendency to express compelling propositions to align with and convince readers of their position. A relatively high proportion of monoglossic resource use was also found in Mesa and Chang's (2010) study of the language of Engagement in the mathematic classroom, and in and Geng and Wharton's (2016) study of the discussion sections of doctoral theses. It may be inferred from these findings that heavy employment of monoglossic resources to engage and position is considered a writing characteristic of novice researchers (Amornrattanasirichok \& Jaroongkhongdach, 2017).

It is worth pointing out that the students in this study balance well in terms of dialogic contractions and expansions. That is, they acknowledge other speakers' voices and engage with them, synchronously. They present themselves as standing with, standing against, or neutral with respect to alternative positions and voices. The analysis uncovered that within the heteroglossic sub-categories, 'entertain' and 'acknowledge' forms were used to provide information, open-up other writers' viewpoints, and to state their position. This may be considered as reader-friendly, given it explicitly invites readers to engage in the discourse, and makes the statement less imposing to readers (Amornrattanasirichok \& Jaroongkhongdach, 2017). However, it was also found that students extensively use modal auxiliaries in their literature review section. This may have been because the students were uncertain about their ability to criticize the referenced sources. As suggested by Martin and White (2005), modalizing locutions are a sign that the writer's knowledge of the subject is to some degree limited and therefore not sufficient to allow for a categorical formulation of the proposition.

Furthermore, the knowledge resource, which aims to ground the viewpoints of external voices and to make space in the ongoing dialog for those who might hold alternative views, is placed third among the use of heteroglossic formulations. It appeared that reporting verbs were often employed in the written texts. Apart from informing the readers with references, acknowledge markers do not show the writer's standpoint with respect to the other voices in the communicative context. This suggests that novice writers take a neutral position towards external voices. The practice to adopt this neutral position is somewhat compatible with many researchers in various disciplines (Amornrattanasirichok \& Jaroongkhongdach, 2017; Petric, 2007; Xie, 2016).

In addition, the high frequency use of 'counter' markers under dialogic contraction indicates that students justify other's viewpoints using countering strategies to convince readers of the validity of their own argument. This phenomenon has also been reported in previous studies including Xie (2016) and Geng and Wharton (2016). These authors found that writers employ the countering strategy in the literature review and discussion sections as a method to justify replacing and correcting alternative views to their own. Lastly, the scarce use of 'distance' markers as a dialogic expansive device presents the authorial voice as explicitly declining to take responsibility for the external voices (Martin \& White, 2055). In other words, the writers treat the cited source impersonally and without judgement. This practice indicates compliance with the norms of the academic discourse community when referring to other voices (Amornrattanasirichok \& Jaroongkhongdach, 2017).

On a final note, based on the above finding and discussion, it can be concluded that Thai EFL undergraduate students tend to apply evaluative language for engagement in their academic research writing. They attempt to conform to professional research writing practices in the literature review section. However, with limited skills in the research area and without being well-trained in how to write research articles, students experience some difficulties expressing their standpoints using evaluative language. They seem to struggle to defend their claims, invoke dialogic alternatives from readers, and properly cite references from other sources. Therefore, to address this problem, the Engagement system as the foundation and basis of negotiating meaning, proposing evidence, and making appeals should be taken into consideration by teachers of academic writing courses for students across all disciplines.

\section{RECOMMENDATIONS}

In the view of the findings and their implication, the following recommendations are made.

1. Future studies may consider the instructional plans of the research report writing class so that researchers may have clearer pictures of how the course is designed and the expected output of the students in the course.

2. Future studies may consider students' engagement throughout the research. Focusing on literature review may provide limited information of students' engagement.

3. The comparison of students' writing may shed light on the variation of students' writing in different tasks.

\section{REFERENCES}

[1] Alramadan, M. M. (2020). The use of Engagement resources in English, Arabic and EFL applied linguistics research: A contrastive study within an Appraisal theoretic perspective. In El-Sadig Y. Ezza (Ed.), Teaching academic writing as a discipline-specific skill in higher education (pp.23-54): IGI Global Publisher of timely Knowledge. https://doi.org/10.4018/9781-7998-2265-3.ch002

[2] Amonrattanasirichock, S., \& Jaroongkhongdach, W. (2017). Engagement in literature reviews of Thai and international research articles in applied linguistics. Paper presented at the International Conferences:DRAL 3/19th ESEA.

[3] Bruce, I. (2014). Expressing criticality in the literature review in research article introductions in applied linguistics and psychology. English for Specific Purposes, 36, 85-96. https://doi.org/10.1016/j.esp.2014.06.004 
[4] Chang, P., \& Schleppegrell, M. (2011). Taking an effective authorial stance in academic writing: Making the linguistic resources explicit for L2 writers in the social sciences. Journal of English for Academic Purposes, 10, 140-151. https://doi.org/10.1016/j.jeap.2011.05.005

[5] Cheng, A. (2011). ESP classroom research: Basic considerations and future research questions. In D. Belcher, A. Johns, \& B. Paltridge (Eds.), New directions in English for Specific Purposes (pp. 44-72). University of Michigan Press.

[6] Cheng, F., \& Unsworth, L. C. (2016). Stance-taking as negotiating academic conflict in applied linguistics research article discussion sections. Journal of English for Academic Purposes, 24, 43-57. https://doi.org/10.1016/j.jeap.2016.09.001

[7] Du, P. M. (2010). An appraisal analysis of English academic article abstracts in journals of linguistics. (Unpublished master dissertation). Shandong Normal University, China.

[8] Flowerdew, L. (2004). The argument for using English specialized corpora to understand academic and professional language. In U. Connor, \& T. Upton (Eds.), Discourse in the professions: Perspectives from corpus linguistics (pp. 11-36). Amsterdam: John Benjamins Publishing Company. https://doi.org/10.1075/scl.16.02flo

[9] Geng, Y., \& Wharton, S. (2016). Evaluative language in discussion sections of doctoral theses: Similarities and differences between L1 Chinese and L1 English writers. Journal of English for Academic Purposes, 22, 80-91. https://doi.org/10.1016/j.jeap.2016.01.001

[10] Hood, S. (2010). Appraising research: Evaluation in academic writing. Basingstoke, UK: Palgrave Macmillan. https://doi.org/10.1057/9780230274662

[11] Hunston, S. (1994). Evaluation and organization in a sample of written academic discourse. In M. Coulthard (Ed.), Advances in written text analysis. London: Routledge.

[12] Hunston, S. (2011). Corpus approaches to evaluation. London: Routledge. https://doi.org/10.4324/9780203841686

[13] Hyland, K. (2005). Metadiscourse: Exploring interaction in writing. London: Continuum.

[14] Hyland, K. (2008). Persuasion, interaction and the construction of knowledge: Representing self and others in research writing. International Journal of English Studies, 8(2), 1-23. https://revistas.um.es/ijes/article/view/49151(accessed 15/3/2021).

[15] Hyland, K. (2011). Researching writing. In B. Paltridge \& A. Phakiti (Eds.), Continuum companion to research methods in applied linguistics. London: Continuum.

[16] Hyland, K., \& Tse, P. (2004). Metadiscourse in academic writing: A reappraisal. Applied Linguistics, 25(2), 156-177. https://doi.org/10.1093/applin/25.2.156

[17] Kitjaroonchai, N., \& Duan, J. (2019). Stance and Engagement use in timed argumentative essays by Asian first-year university students studying English as a foreign language. Human Behavior, Development and Society, 22(3), 105-115.

[18] Kong, K. C. C. (2006). Linguistic resources as evaluators in English and Chinese research articles. Multilingual, $25,183-216$. https://doi.org/10.1515/MULTI.2006.012

[19] Kwan, B. S., Chan, H., \& Lam, C. (2012). Evaluating prior scholarship in literature reviews of research articles: A comparative study of practices in two research paradigms. English for Specific Purposes, 31, 188-201. https://doi.org/10.1016/j.esp.2012.02.003

[20] Lee, J., \& Deakin, L. (2016). Interactions in L1 and L2 undergraduate student writing: Interactional metadiscourse in successful and less-successful argumentative essays. Journal of Second Language Writing, 33, 21-34. https://doi.org/10.1016/j.jslw.2016.06.004

[21] Martin, J. R., \& White, P. R. R. (2005). The language of evaluation: Appraisal in English. New York: Palgrave Macmillian. https://doi.org/10.1057/9780230511910

[22] Mei, W. S. (2006). Creating a contrastive rhetorical stance: Investigating the strategy of problematization in students' argumentation. RELC Journal, 37(3), 329-353. https://doi.org/10.1177/0033688206071316

[23] Mesa,V., \& Chang, P. (2010). The language of engagement in two highly interactive undergraduate mathematics classrooms. Linguistics and Education, 21, 83-100. https://doi.org/10.1016/j.linged.2010.01.002

[24] Mo, X. Y. (2010). On the engagement resources of literature reviews in English academic articles. (Unpublished master dissertation). Ningbo University, China

[25] Mori, M. (2017). Using the appraisal framework to analyze source use in essays: A case study of engagement and dialogism in two undergraduate students' writing. Functional Linguistics. 4(11), 1-22. https://doi.org/10.1186/s40554-017-0046-4

[26] Ngo, T., \& Unsworth, L. (2015). Reworking the Appraisal framework in ESL research: refining attitude resources. Functional Linguistics. 2(1). https://doi.org/10.1186/s40554-015-0013-x

[27] Petric, B. (2007). Rhetorical functions of citations in high- and low-rate master's theses. Journal of English for Academic Purposes, 6, 238-253. https://doi.org/10.1016/j.jeap.2007.09.002

[28] Salom, L. G., \& Monreal, C. S. (2014). Writers' positioning in literature reviews in English and Spanish computing doctoral theses. Journal of English for Academic Purposes, 16, 23-39. https://doi.org/10.1016/j.jeap.2014.08.002

[29] Swales, J. (1990). Genre analysis: English in academic and research settings. Cambridge University Press: Cambridge, UK

[30] Swales, J. (2004). Research genres: Exploration and applications. Cambridge: Cambridge University Press.https://doi.org/10.1017/CBO9781139524827

[31] Thompson, G., \& Ye, Y. (1991). Evaluation of the reporting verbs used in academic papers. Applied Linguistics, 22(1), 58-79. https://doi.org/10.1093/applin/22.1.58

[32] White, P. (2001). Engagement. In Appraisal: An overview. Retrieved from http://grammatics.com/appraisal/AppraisalGuide/Framed/Frame.htm. (accessed 15/3/2021).

[33] Xie, J. (2016). Direct or Indirect? Critical or uncritical? Evaluation in Chinese English-major MA thesis literature review. Journal of English for Academic Purposes, 23, 1-15. https://doi.org/10.1016/j.jeap.2016.05.001

Rungkarn Pratumtong: a lecturer at the Department of English, Faculty of Humanities, Naresuan University, Phitsanulok, Thailand. Her research interests cover discourse analysis, language learning strategies, active learning, and assessment. 
Paweena Channuan: an Assistant Professor at the Department of English, Faculty of Humanities, Naresuan University, Phitsanulok, Thailand. Her current research interests are Systemetic Functional Linguistics, English language teaching, blended learning, and language teaching.

Wannaprapha Suksawas: an Assistant Professor at Sukhothai Thannathirat Open University, Nonthaburi Province, Thailand. Her research interests are Appraisal Theory, Metadiscourse, CLIL and Second Language Acquisition. She is the corresponding author of this paper. 